\title{
Relationship of Attention Deficit-hyperactivity Disorder on the Spectrum of Anorexia Nervosa to Obesity: A Case Report
}

\author{
(1) Tuğba Kalyoncu1, (1) Burak Baytunca2, (1) Sezen Köse3, (1) Burcu Özbaran3 \\ 'University of Health Sciences, İmir Tepecik Training and Research Hospital, Clinic of Child Psychiatry, Izmir, Turkey \\ 2University of Health Sciences, Erzurum Regional Training and Research Hospital, Clinic of Child Psychiatry, Erzurum, Turkey \\ ${ }^{3}$ Ege University Faculty of Medicine, Department of Child Psychiatry, İzmir, Turkey
}

\begin{abstract}
Eating disorders are a growing health problem among adolescents and have increasingly become the focus of studies due to their prevalence. Both obesity and anorexia nervosa are associated maladaptive eating behaviours that may be relevant to development. With this case report, it is intended to discuss the diagnosis and management of a female adolescent patient, diagnosed with obesity and attention deficit-hyperactivity disorder (ADHD). A 16-year-old, female, obese adolescent was referred to our in-patient clinic due to maladaptive eating styles, depressive symptoms and ADHD symptoms. Her early course of illness, diagnostic process, treatment and short-term outcome are described. At the time of discharge, the patient's Clinical Global Impression (CGI) scale severity item score was 2 (borderline mentally ill) and CGI improvement item score was 2 (much improved). We report the present case with the purpose of establishing a pediatric approach to obesity, a disease not included in Diagnostic and Statistical Manual-5 under eating disorders, yet we believe it shares common underlying genetic and environmental causes.

Keywords: Anorexia, obesity, attention deficit hyperactivity disorder, adolescent
\end{abstract}

\section{Introduction}

The prevalences of both obesity (OB) and, at the other end of the spectrum, anorexia nervosa (AN), a severe and complex biological and psycho-social illness, have increased dramatically in the past few decades (1). Both $O B$ and $A N$ are associated with maladaptive eating styles that may be relevant to their development (2). Previous research has therefore addressed the problem of children's eating behaviour and has highlighted a number of key factors such as personality traits, obesogenic environment and peer bullying. This report aims to examine particularly the impact of the mother's own eating behaviour with a focus on parental control and the attention deficit-hyperactivity disorder (ADHD) of the case.

\section{Case Report}

A 16-year-old female patient was referred to our outpatient clinic for psychiatric evaluation prior to a procedure of gastric bariatric surgery relating to morbid $\mathrm{OB}$. The patient and her mother had been seeking surgical treatment for the case's morbid OB for several months. She was born in term without any medical problem and her neurodevelopment milestones were within normal limits. She was the only child of her parents who divorced when she was a 2-year-old. During her 
toddlerhood and preschool years, her grandmother was the principal caregiver. Her mother was working as a nurse in a hospital and had no leisure time to share with her daughter because of her occupation. The case did not present any psychosocial problems during elementary and secondary school years but was over-weighted during both of these terms. However, she was exposed to peer victimisation due to her physical appearance in high school. At the time of her first psychiatric examination, she weighed 122 kilograms and her body mass index (BMI), kg/m² was 42.2 (>97 percentile) (Figure 1). It was noticed that she had attention deficiency, impulsivity and problems of executive functions, therefore she was diagnosed with ADHD. According to Turgay (3) Diagnostic and Statistical Manual (DSM) of Mental Disorders, Fourth Edition-Based Child and Adolescent Behavior Disorders Screening and Rating scale-Parent Form DSM-5 Parent form (4), ADHD symptom severity score was 37. The patient was hospitalized for observation and regulation of her eating attitudes/behaviors and psychoeducation for her eating disorders. Methylphenidate treatment was started and gradually titrated up to $54 \mathrm{mg} /$ day long acting form without any adverse effect. Worthy of note, her mother was so thin, to the degree of a similar appearance to AN. Her mother's BMI was 17.2 (Figure 1). She expressed her strong wish to restrain herself from binge eating and excessive sport training after having meals. Interestingly her mother was trying to prevent the patient's school attendance because of her increased eating when she was at school as the patient was not under her mother's control at school. Additionally, her mother's determination for the patient to have surgical intervention made us to consider excessive parental controlling behaviour on her daughter. She was referred to adult psychiatry and diagnosed with $\mathrm{AN}$ and ADHD. To understand the psychodynamic basis of the case and the patient's relationship with her mother, a Thematic

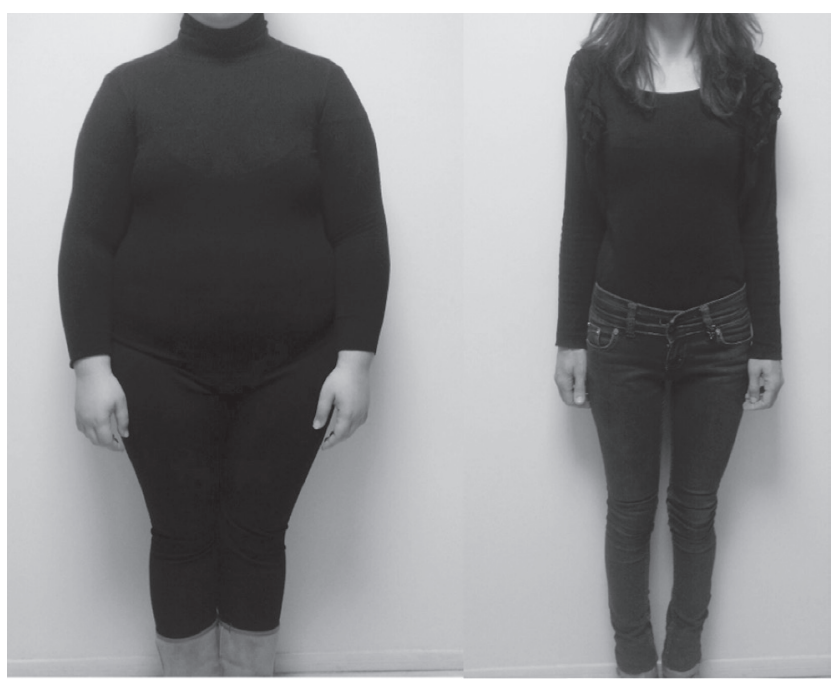

Figure 1. Case and her mother
Apperception test was administered and resulted in the findings of the oral stage of the psychosexual development and autonomy problems. During the patient's inpatient days, her mother was educated concerning her over-protective control over her child. The patient lost 5 kilograms in a week and major improvements were observed regarding her impulsive eating attitudes. The Clinical Global Impressions (CGI) scale (5) severity score at the time of in-patient treatment was 6 (severely ill). At the time of discharge, the patient's CGI severity item score was 2 (borderline mentally ill) and CGI improvement item score was 2 (much improved).

\section{Discussion}

The increase in the scientific literature about eating disorders and $\mathrm{OB}$ have many things in common. To date, $\mathrm{OB}$ has been considered as primarily a somatic disorder and is not classified as an eating disorder in DSM-5. However, OB, like $A N$, is considered a growing problem, and is thought to be generally increasing in Western countries. There are a range of suggestions about the etiology of $O B$ such as underlying genetic, endocrine and metabolic factors. Barkley (6) has described ADHD as a disorder of behavioral inhibition, a component of which is the ability to selfregulate. Also, increasing evidence points to a significant association between $\mathrm{ADHD}$ and $\mathrm{OB}$ (7). It is possible that the behavioral and cognitive features of ADHD give rise to pathological eating patterns as in our case. Also, parental attitudes are particularly important in psychiatric disorders, including ADHD (8). Parents who have higher levels of parental control, expressed emotionally critical comments, hostility, or emotional over involvement and negate their child's emotional needs are more likely to have children who develop eating disorders (9-11). There have also been several suggestions concerning family variables in the development of $\mathrm{OB}$. One of these is that of a family being characterised by a dominant mother and a submissive father. As in the case of this patient, it can be assumed that children living in an unfavourable home environment will have less access to regular eating attitudes and healthy interactions, which may in turn affect their risk of becoming overweight. Also, highly controlling and restrictive parental feeding behaviour contributes to a positive energy balance and higher BMI by interfering with children's ability to self-regulate their energy intake $(12,13)$. Therefore, promoting a child's ability to selfregulate their intake and to develop sensitivity to internal needs is crucial. In addition, people with eating disorders tend to misjudge their own body shapes, believing that they are fatter than they actually are, and have a strong desire to be thinner. Therefore, it is conceivable that parents with eating disorders may misjudge their children's size or want them to be thin and thus limit their food intake (14). The relation between maternal eating behavioural characteristics and 
childhood $O B$ remains an important field of research. There are considerable implications for clinical work on mothers with eating disorders and it is likely that early intervention may be important in order to prevent the intergenerational transmission of such issues. In conclusion, the aim of this case study is to point out the possibility of demonstrating $\mathrm{AN}$ and $\mathrm{OB}$ as two polarities on the same disease spectrum; and the role of ADHD comorbidity in eating disorders, which presents itself both in the child and in the parent.

\section{Ethics}

Informed Consent: Informed consent was given by all parties prior to this study.

Peer-review: External and internal peer-reviewed.

\section{Authorship Contributions}

Surgical and Medical Practices: T.K., B.B., B.Ö., S.K., Concept: B.Ö., Design: T.K., Data Collection and Processing: T.K., B.B., Analysis and Interpretation: B.Ö., S.K., Literature Search: T.K., B.B., Writing: T.K., B.B.

Conflict of Interest: No conflict of interest was declared by the authors.

Financial Disclosure: The authors declared that this study received no financial support.

\section{References}

1. Bulik CM, Sullivan PF, Tozzi F, Furberg $H$, Lichtenstein $P$, Pedersen NL. Prevalence, heritability, and prospective risk factors for anorexia nervosa. Arch Gen Psychiatry 2006;63:30512.

2. Krug I, Villarejo C, Jiménez-Murcia S, et al. Eating related environmental factors in underweight Eating Disorders and Obesity. Are there common vulnerabilities during childhood and early adolescence. Eur Eat Disord Rev 2013;21:202-8.
3. Turgay A. Disruptive Behavior Disorders Child and Adolescent Screening and Rating Scales for Children, Adolescents, Parents and Teachers. West Bloomfield (Michigan): Integrative Therapy Institute Publication, 1994.

4. Ercan ES, Amado S, Somer O, Çikoglu S. Development of a test battery for the assessment of attention deficit hyperactivity disorder. Turk J Child Adolesc Ment Health 2001;8:132-44.

5. National, Institute of Mental Health. CGI (Clinical Global Impression) scale. Psychopharmacol Bull 1985:21.

6. Barkley RA. Attention-deficit/hyperactivity disorder and selfregulation: taking an evolutionary perspective on executive functioning. In: Baumeister Roy F, Vohs Kathleen D (eds). New York, NY, US, Guilford Press, 2004;301-23.

7. Martínez de Velasco R, Barbudo E, Pérez-Templado J, Silveira $B$, Quintero J. Review of the association between obesity and ADHD. Actas Esp Psiquiatr 2015;43:16-23.

8. Lahey BB. Out of the funhouse mirrors: steps toward understanding the role of parenting in maladaptive child development. I Am Acad Child Adolesc Psychiatry 2011;50:975-7.

9. Polivy J, Herman CP. Causes of eating disorders. Annu Rev Psychol 2002;53:187-213.

10. Kluck AS. Family factors in the development of disordered eating: integrating dynamic and behavioral explanations. Eat Behav 2008;9:471-83.

11. Blodgett Salafia EH, Jones ME, Haugen EC, Schaefer MK. Perceptions of the causes of eating disorders: a comparison of individuals with and without eating disorders. I Eat Disord 2013;3:32.

12. Fisher JO, Birch LL. Restricting access to palatable foods affects children's behavioral response, food selection, and intake. Am J Clin Nutr 1999;69:1264-72.

13. Birch LL, Davison KK. Family environmental factors influencing the developing behavioral controls of food intake and childhood overweight. Pediatr Clin North Am 2001;48:893-907.

14. Patel $P$, Wheatcroft R, Park RJ, Stein A. The children of mothers with eating disorders. Clin Child Fam Psychology Rev 2002;5:119. 